\title{
Guibert de Nogent (c.1055 - c.1125)* \\ entre História e exegese no século XII
}

\section{Guibert of Nogent (c.1055 - c.1125) \\ between History and exegesis in the 12th century}

\author{
J OÃO GOMES DA SILVA FILHO \\ Université Paris - I Sorbonne. \\ Bolsista CAPES \\ clairabelard@yahoo.fr
}

\begin{abstract}
E existe um trabalho próprio à duração que desordena as telas e desperta ou adormece as estatuas. Os torsos se completam porque o tempo quebrou as cabeças.

Maurice Blanchot ${ }^{1}$
\end{abstract}

RESUMO Nas pesquisas sobre a Idade Média, a compreensão dos sentidos e das bases de constituição de uma narrativa e de um pensamento historiográfico medievais ocupam um espaço fundamental, porém, ainda hoje, resta como uma questão em aberto o modo como se deu a relação profunda deste tipo de narrativa com o conjunto mais amplo da produção intelectual no periodo. Como os textos historiográficos produzidos entre o final do seculo XI e o inicio do seculo XII são obras quase exclusivas do ambiente monástico decidimos colocar a questão em detalhe sobre um autor beneditino, Guibert

Artigo recebido em: outubro/2007.

1 BLANCHOT, M. Le Musée, I'Art et le Temps. In: L'Amitié. Paris: Gallimard, 2004, p.45. 
de Nogent, cuja obra exegética extremamente original é muito pouco estudada e conhecida, mas que constitui a estrutura fundamental de seu pensamento tanto do ponto de vista espiritual quanto historiográfico.

Palavras-chave tropologia, Historiografia, monasticismo

ABSTRACT Among the researches on the Middle Ages the comprehension about the senses and bases for the constitution of a medieval Historiography narrative and thought occupies an essential place but, presently, it remains as an open question how it is done deeply the relationship of that kind of narrative with the entirely and vaster intellectual production in this period. As we know, the Historiography texts between the end of the eleventh and the beginnings of the twelfth-century are most exclusively the works of a monastic environment, so I have decided to put the question on detail about a benedictine author, Guibert of Nogent, whose extremely orig inal exegetical work is not very studied and known, but constitutes the fundamental structure of his thought at the same time spiritual and about the historiography.

Keywords tropology, Historiography, monasticism

\section{Introdução}

O tema desta apresentação baseia-se, antes de tudo, em duas constatações: a primeira delas é uma evidencia, já bem estabelecida, de que a Idade Média e em particular o século XII possuiu um discurso historiográfico extremamente ativo, sobretudo no ambiente monástico mesmo que os autores responsáveis pela produção destes textos não tenham sido eles mesmos historiadores. Em meio à intensa dinâmica do claustro, seja ela do antigo ou do novo monasticismo, a escrita da história não é uma preocupação essencial vindo, portanto a se apresentar como necessária em momentos específicos e com objetivos específicos, estes últimos nem sempre totalmente claros aos nossos olhos. A segunda constatação é a de uma falta, decorrente diretamente da primeira e que só pode ser apresentada como uma questão em aberto: se a escrita da história, se o registro narrativo de uma dada memória, é uma atividade que possui um sentido específico mesmo que marginal no interior da produção monástica do século XII, qual é a sua relação com uma reflexão monástica que encontra seu lugar próprio muito mais em meio às linhas de uma especulação teológica - se podemos falar aqui de uma teologia monástica ${ }^{2}$ - que se aproxima e nutre o pensamento das novas escolas urbanas,

2 Como nos ensinam os trabalhos já clássicos de LECLERCQ, J. L'Amour des Lettres et le Désir de Dieu. Initiation aux auteurs monastiques du Moyen Age, Paris: Cerf, 1990 (1957), LECLERCQ, J. The Renewal of Theology, In: BENSON, R. L., CONSTABLE, G. with LANHAN, C. D. (eds.), Renaisssance and Renewal in the Twelfth-Century, 
ou em meio a todo o universo exegético de explicação e compreensão do texto bíblico? Em outras palavras, se o discurso historiográfico não pode ainda ser visto como autônomo, de quais bases teóricas ele depende para que, neste momento, ele possa ganhar toda a sua consistência formal e por que não, metodológica?

Diante da dificuldade em responder a esta questão de uma maneira sintética e geral me parece um bom começo nos questionarmos sobre 0 que envolve a composição pontual, para uma primeira abordagem, de um texto historiográfico medieval levando em consideração toda uma série de pesquisas essenciais já realizadas sobre a escrita da historia na Idade Média. Nos permitimos aqui, portanto, não citar exaustivamente uma bibliografia já bastante vasta, sendo suficiente mencionar os trabalhos de Bernard Guenée ${ }^{3}$, em primeiro lugar, pela força da demonstração e pela dissecação original dos principais elementos constitutivos do pensamento historiográfico medieval e das praticas a ele subjacentes; de J anet Coleman que introduz a problemática discursiva no contexto do registro e da perpetuação da memória4; de Dominique Boutet ${ }^{5}$ pela abordagem formal e "literária" da composição textual de tais relatos; de Michel Clanchy ${ }^{6}$ pela importância manifesta e sabida de seu estudo sobre a escrita, a escritura e o registro diplomático como paradigma cultural em relação a uma sociedade pensada até então, salvo algumas exceções, como essencialmente oral ${ }^{7}$; Karl Ferdinand Werner ${ }^{8}$ cuja obra seria difícil a resumir, mas que abre interessantes perspectivas sobre a relação entre história, historiografia e política; e por fim, J acques Le Goff9, como referência mais do que evidente para uma reflexão sobre a crítica das fontes utilizadas pelo historiador atual.

Partindo desta base e do que foi dito acima sobre a não exclusividade e a falta de autonomia imanente do discurso historiográfico medieval nos propomos a pensar sobre as confluências teóricas que em um dado ambiente e, no nosso caso, sob a pluma de um determinado autor, deram origem a este

Toronto/Buffalo/London: University of Toronto Press and Medieval Academy of America, 1991, p.69-87 e de CHENU, M.-D. La Théologie au Xlle siècle, Paris: Vrin, 1966 (1957). Deve-se mencionar também: GREGOIRE, R. Bulletin de théologie monastique. Studia monastica 10 (1968), p.161-180; GREGOIRE, R. Esiste una teologia monastica? Inter fratres 27 (1977), p.115-120; GILSON, E. La Théologie Mystique de S. Bernard, Paris: Vrin, 1934.

3 GUENEE, B. Histoire et Culture Historique dans l'Occident Médiéval, Paris: Aubier, 1980.

4 COLEMAN, J. Ancient and Medieval Memories. Studies in the reconstruction of the past, Cambridge: Cambridge Univ. Press, 1995; COLEMAN, J. Universal History secundum physical et ad litteram in the twelfth-century, In: GENET, J. P. (ed), L'Historiographie Médiévale en Europe. Actes..., Paris: Editions du CNRS, 1991, p.263-275.

5 BOUTET, D. Formes Littéraires et Conscience Historique aux Origines de la Littérature Française. 1100-1250, Paris: PUF, 1999.

6 CLANCHY, M. T. From Memory to Written Record. England 1066-1307, Oxford: Blackwell, 1993.

7 Neste sentido não será excessivo mencionar o importante trabalho e os avanços propostos por STOCK, B. The Implications of Literacy. Written language and models of interpretation in the Eleventh and Twelfth Centuries, Princeton/New J ersey: Princeton University Press, 1983, em especial toda a parte I «Oral and Written » e toda a parte II «Textual Communities ». Sobre Guibert de Nogent e o De pigneribus sanctorum ver parte III, cap. 1 « Guibert de Nogent and 'popular' culture », p.244-251, mas do qual será questão também nos capítulos seguintes.

8 WERNER, K. F. Les «structures » de l'histoire à l'âge du christianisme. Histoire de l'Historiographie, 10, (1986), p.36-47 ; WERNER, K. F. Dieu, les rois et l'Histoire, In: DELORT, R. (dir.) et études rassemblées par IOGNA-PRAT, D. La France de l'an Mil, Paris; Seuil, 1990, p.264-281.

9 LE GOFF, J. Histoire et Mémoire, Paris: Gallimard, 1988. 
tipo de discurs $0^{10}$. Compreender a especificidade de um pensamento não é, portanto, uma tarefa das mais simples. Temos clareza do peso inegável de uma tradição literária voltada ao registro da memória que se projeta sobre todo o período medieval a partir dos autores romanos clássicos, da forte influência patristica em geral como também da autoridade específica de um Beda o Venerável e de um Eusébio de Cesárea. Não negligenciamos tampouco as determinações mais objetivas, mais concretas, que possam ter tornado viável e desejável a composição dos textos. Porém, o que nos interessa e ao que nos ateremos essencialmente hoje é a formulação de uma hipótese segundo a qual, no século XII, não se produz apenas um novo interesse pela escrita da historia, tema já bastante discutido como um dos elementos de um pretendido "renascimento", mas mais profundamente, uma nova concepção temporal e da percepção do tempo.

Peter Classen tem razão ao afirmar que a produção historiográfica do final do século XI e do inicio do século XII foi bastante estimulada por três fenômenos: a fundação de um "estado" Anglo-Normando por Guilherme 0 Conquistador, as cruzadas e as comunas ${ }^{11}$. 0 autor sobre o qual nos interessamos, Guibert de Nogent, é decisivamente tocado por estes dois últimos, como veremos mais adiante. Guy Lobrichon, por sua parte, leva a reflexão mais adiante ao precisar que o empreendimento das cruzadas e, sobretudo da primeira é fundamental para a compreensão de toda uma nova mentalidade e de uma nova sociedade que se fazem presentes neste momento e imediatamente depois, erigidas sobre uma nova concepção dos limites do mundo e da Cristandade ${ }^{12}$. Deste movimento de universalização territorial e simbólica é uma outra história que se apresenta, uma historia também universal não apenas na expressão e na abrangência de seu recorte cronológico teleologicamente articulado pelo Cristianismo, mas também em seu sentido mais profundo presente em narrativas pontuais como a de Guibert. De uma maneira geral estes dois sentidos universalizantes da história que se começa a produzir no século XII estão impregnados por uma interpretação profética dos fatos sobre a qual retornaremos mais adiante ${ }^{13}$. Mas há ainda outros fatores a serem considerados e que dizem respeito diretamente aos lugares onde essa nova história se produz. Se dissemos acima que a atividade se concentra quase exclusivamente neste momento no interior dos muros dos monastérios é bem evidente que não são todos, mas uma pequena minoria,

10 Poderíamos muito bem colocar a questão sob a perspectiva de outros nomes do mesmo período como Raoul Glaber, Suger, Otton de Freising, Hugo de Fleury ou Fulcher de Chartres, por exemplo. Com uma abordagem diferente da nossa, mas extremamente instrutiva : ORTIGUES, E. et IOGNA-PRAT, D. Raoul Glaber et l'historiographie clunisienne. Studi Medievali, ser. 3, 26 (1985), p.537-572.

11 CLASSEN, P. Res gestae, Universal History, Apocalypse. Visions of past and future, In: BENSON, R. L., CONSTABLE, G. with LANHAN, C. D. (eds.), Renaisssance and Renewal in the Twelfth-Century, Toronto/Buffalo/London: University of Toronto Press and Medieval Academy of America, 1991, p.387-417 (p.388).

12 LOBRICHON, G. 1099. Jérusalem conquise, Paris: Seuil, 1999. Ver também : LOBRICHON, G. Héloïse. L'amour et le savoir, Paris: Gallimard, 2005, p.175.

13 COLEMAN, J. Universal History... (nota 4), p.204. 
que possuem os meios materiais e intelectuais para realizar um tal trabalho. Estes monastérios são geralmente os mais prestigiosos; um prestigio que provém de uma bem estabelecida e abrangente influencia territorial que se traduz em uma influência social, de uma autoridade calcada no nome de seu fundador ou patrono, mas a partir de então, também, na excelência de sua produção teórica. E neste último caso são bem as novas fundações reformadoras que se destacam. Antes que possamos falar então da grande importância das escolas catedrais urbanas é preciso não relegar a um plano secundário toda a produção monástica a força de recairmos em uma concepção evolucionista da historia do pensamento no Ocidente. Neste restrito ambiente monástico se desenvolve, concomitantemente ao novo interesse pela narrativa historiográfica, todo um aparato de crítica textual extremamente importante: é neste momento que é composta a Glosa Ordinaria sob o impulso da escola de Laon, que Hugues de Saint-Victor compõe seu Didascalicon e o De scripturis et scriptoris, que se renova e recria-se o gênero enciclopédico em autores como Alexandre Nequam (De naturis rerum) ${ }^{14}$, que o Elementarium de Papias compos to no século XI é largamente utilizado. Trata-se de todo um universo técnico voltado para a instrumentalização do conhecimento da sacra pagina e para o trabalho primordial dos comentários do texto sagrado.

Assim podemos estender nossa questão, a saber: se os três fenômenos contextuais mencionados acima, e com maior peso o efeito produzido pela primeira cruzada, podem ser considerados como estimuladores de um novo interesse historiográfico resta saber como se da a relação entre esta atividade e o conjunto de um pensamento que a envolve e que the fornece a perspectiva e o sentido profundo de sua narrativa.

\section{A importância do testemunho de Guibert de Nogent}

Guibert de Nogent é sem duvida um dos autores medievais dos mais surpreendentes. Sua extensa obra compreende entre seus textos mais conhecidos uma dita autobiografia: Monodiae ${ }^{15}$, da qual provém praticamente toda a informação disponível sobre nosso autor; um dos primeiros relatos da Primeira Cruzada: Dei gesta per Francos ${ }^{16}$; um tratado polêmico sobre 0 problema da reprodução e da crença nas relíquias de santos: De pigneribus sanc torum ${ }^{17}$. Mas Guibert de Nogenté antes de tudo um exegeta profícuo e 0

14 Ver: DAHAN, G. Encyclopédies et exégèse de la Bible aux XIle et XIlle siècles. Cahiers de Recherches Médiévales, 6 (1999), p.1-24; RIBÉMONT, B. La 'Renaissance' du Xlle siècle et l'Encyclopédisme, Paris: H. Champion, 2002.

15 GUIBERT DE NOGENT, Autobiographie, éd. et trad. E- R. Labande, Paris: Belles Lettres, 1981. Existe também uma nova tradução inglesa de P. Archambault, A Monk Confession, The Memoirs of Guibert de Nogent, University Park, PA: Pennsylvania State University Press, 1995.

16 GUIBERT DE NOGENT, Dei gesta perFrancos et cinq autres textes, éd. R. B. C. Huygens, Turnhoult: Brepols, [CCCM 127A], 1996. E a bela tradução de M.-C. Garand, Geste de Dieu par les Francs, Turnhoult: Brepols, 1998.

17 GUIBERT DE NOGENT, De pigneribus sanctorum, éd. R. B. C. Huygens, Turnhout: Brepols, [CCCM 127], 1993, p.79-175. 
essencial de seu trabalho repousa em seus comentários bíblicos bem como grande parte de sua originalidade. Podemos destacar, entre outros, um longo comentário sobre o Gênese: o Moralia Geneseos ${ }^{18}$; as duas séries sobre os doze profetas menores, a primeira compreendendo os comentários sobre Oséias, Amos e as Lamentações de J eremias e a segunda, ainda inédita, sobre os demais profetas restantes salvo Ageu e Malaquias: as Tropologiae in prophetis ${ }^{19}$.

Durante toda a Idade Média, como é sabido, as Escrituras foram lidas e interpretadas sem interrupção, mesmo que de acordo com o estado dos conhecimentos atuais ainda apareçam períodos de menor e maior atividade que refletem não apenas a oscilação do interesse exegético, mas também as lacunas que a escassez de fontes deixam entreabertas. Esta é a atividade chave e a base do desenvolvimento doutrinário ao longo de todo o período. No entanto este grande movimento interpretativo não é algo fechado e homogêneo e mesmo a transmissão dos comentários que fazem autoridade incontestável não impede uma relativa implicação pessoal do "compilador" através de sua escolha e da síntese proposta, como vêem nos comprovando as mais recentes pesquisas sobre um autor do século $X$ como Haymon d'Auxerre ${ }^{20}$.

De maneira esquemática os autores medievais distinguem três ou quatro níveis de interpretação possíveis. O sentido "literal" ou "histórico", o "alegórico", o "tropológico" ou moral e finalmente o sentido "anagógico". Ao longo da Idade Média veremos as mais diversas articulações entres estes níveis de interpretação que sintetizam uma verdadeira hermenêutica cristã21. 0 que nos interessa neste momento é o fato de que até o inicio do século XII, mesmo que o nível tropológico se faça presente de maneira importante, como nos prova a herança ainda viva de Gregório o $\mathrm{Grande}^{22}$, por exemplo, ou os desenvolvimentos interpretativos dos cistercienses, ele não foi objeto de um aprofundamento particular ${ }^{23}$. Este recente movimento em direção de uma mais intensa interpretação moral da Bíblia do qual Guibert de Nogent é um dos primeiros grandes representantes é de extrema importância para a compreensão e a definição de uma exegese propriamente monástica ${ }^{24}$.

18 GUIBERT DE NOGENT, Moralia Geneseos, PL 156, cols. 19-338.

19 Primeira série : Tropologiae in Osee, J eremiam et Amos, PL 156, cols. 337-488. Para a segunda série apenas quatro manuscritos chegaram até nós: Paris BnF lat. 17282 ; Chapel Hill, Wilson Library 516 ; Troyes BM 658 ; Soissons BM 73.

20 Ver a síntese recente de SHIMAHARA, S. Haymon d'Auxerre. Études et Travaux 2004-2005, CEM d'Auxerre, 9, (2005), p. 133-142.

21 Até o momento presente encontrei apenas um testemunho de uma posição contrária ao emprego da noção de «hermenêutica cristã » ou «medieval »: BOULNOIS, O. L'Histoire, Le Corps, L'Architecte: exégèse médiévale et herméneutique, In: GREISCH, J . (ed.), Comprendre et Intérpreter. Le Paradigme Herméneutique de la Raison, Paris: Beauchesne, 1993, p.93-100.

22 GREGOIRE LE GRAND, Moralia in J ob, éd. M. Adriaen, Turnhoult: Brepols, [CCSL 143-143B], 1979. E os três volumes já publicados pela coleção Sources Chrétiennes: L. I-II (vol.32bis) ; L. XI-XIV (vol.212) ; L. XV-XVI (vol.221).

23 LUBAC, H. de. Exégèse Médiévale. Les quatre sens de l'Ecriture, Paris: Aubier, 1954-1964, 4 vols.

24 Um debate que resta ainda em aberto e que foi lançado por J ean Leclercq (nota 2). Ver também DAHAN, G. L'exégèse chrétienne de la Bible en Occident Médiéval, XIle-XIVe siècle, Paris: Cerf, 1999, p.86: «Cet ensemble de caractères semble conférer une relative unité de ton à l'exégèse monastique. Le plus remarquable me semble 
Nosso autor opta por concentrar-se exclusivamente a tropologia, salvo em breves exceções, abandonando um certo procedimento pedagógico corrente que encaminhava o "leitor/ouvinte" desde o nível literal até os mais elevados e difíceis níveis espirituais de compreensão. E a escolha de Guibert é deliberada, como ele mesmo nos diz em sua "autobiografia": [o sentido] moral (moralia) é em nossa época muito mais útil que o alegórico, pois, se a fé que vem de Deus permanece intacta, os modos são quase por toda parte corrompidos por múltiplos vícios ${ }^{25}$. Guibert compõe esta obra por volta de 1114/1115 após um conturbado período ao qual o abade de Nogent não foi, sem duvida, insensível: aproximadamente cinco ou seis anos depois de ter concluído sua história da primeira cruzada com o sentimento paradoxal do narrador que não transmite os fatos a partir de sua experiência direta. Por outro lado o "acontecimento" cruzadístico alterou as relações de força no seio da aristocracia do Norte da França da qual provém Guibert e em meio a qual ele viveu, situação esta que teve conseqüências diretas sobre a vida dos religiosos da região do Laonnais, como nos explica minuciosamente a tese de Dominique Barthélemy sobre os senhores de Coucy ${ }^{26}$. A "autobiografia" vem à luz também três a quatro anos depois do conturbado e violento período que levou a termo a Comuna de Laon, narrada no terceiro e ultimo livro das Monodiae. Neste sentido Guibert se apropriará da tropologia como instrumento privilegiado da predicação, seguindo o exemplo de Gregório o Grande por um lado e por outro os ensinamentos de Anselmo de Canterbury ${ }^{27}$, se posicionando assim relativamente próximo da atualidade dos cistercienses $^{28}$; no entanto ele levará sua interpretação a um novo limite, passando da generalidade moral à uma análise extremamente fina e complexa da interioridade e dos movimentos da alma, ou seja, da consciência, das vontades, dos afetos, das intenções e da memória. Só encontraremos uma atenção do mesmo nível à interioridade em autores já comprometidos com a nova escolástica como Abelardo ${ }^{29}$ e Richard de Saint-Victor (este ultimo mesmo que não integralmente) $)^{30}$. Infelizmente não poderemos aqui explicar detalha-

être l'importance accordée à la tropologie; elle contribue à donner aux commentaires monastiques leur saveur si particulière » e por fim, PRANGER, M. B. Mystical Tropology in Bernard of Clairvaux. Bijdragen : tijdschrift voor philosophie en theologie, 52 (1991), p.428-433.

25 Autobiographie, éd. Labande (note 15), L. I, XVIII, p.146.

26 BARTHÉLEMY, D. Les deuxâges de la seigneurie banale: Coucy (Xle-Xllle siécles), Paris: Publications de la Sorbonnne, 1984 [séconde édition augmenté d'une postface]; BARTHÉLEMY, D. Lectures de Guibert de Nogent (Autobiographie, III, t.11). Les Origines des Libertés Urbaines. Actes du Congrès des historiens médiévistes de l'enseignement supérieur (Rouen, 7-8 juin 1985), Rouen: Publications de l'Université de Rouen, 1990, p.175-192.

27 Autobiographie (note 15), L. I, XVII, p.138-140. Ver também: PELIKAN, J . A first-generation Anselmian, Guibert of Nogent, In: CHURCH, F. F. and GEORGE, T. (eds.), Continuity an Discontinuity in Church History. Essays presented to G. H. Williams, Leiden: Brill, 1979, p.71-82; LABANDE, E. R. Guibert de Nogent, disciple et témoin d'Anselme au Bec. Spicilegium Beccence II, (1984), p.608-625.

28 Ver: BOQUET, D. L'Ordre de l'Affectau moyen Âge. L'anthropologie affective d'Aelred de Rievaulx, Caen: Publications du CRAHM, 2005, esp. p.103-108.

29 Sobretudo sua Ethica, et trad. D. E. Luscombe, Oxford: Clarendon Press, 1972.

30 Sobretudo o Benjamin minor (Les douze patriarches ou Beniamin minor), éd. et trad. J. Châtillon et M. DuchetSuchaut, Paris: Cerf [Sources Chrétiennes, 419], 1997; De eruditione hominis interiori, PL 196, cols. 1229-1366; 
damente o sistema interpretativo de Guibert nem tirar em pouco tempo todas as suas conseqüências, no entanto, para o que nos ocupa neste momento é importante ter em mente que a análise tropológica de nosso autor não apenas perscruta a interioridade e a subjetividade, mas é ela mesma um processo de atualização de subjetividade dada à exigência suprema e constante do auto julgamento e de uma conduta exemplar ${ }^{31}$.

Assim, como se apresenta o registro e a narrativa historiográfica para um autor que se debruça conscientemente sobre a tropologia e negligencia a alegoria, a qual confere portanto uma das bases interpretativas mais correntes da narrativa histórica? ${ }^{32} \mathrm{O}$ u ainda, como ele se serve, finalmente, do nível literal ou histórico, este que é o mais elementar e o mais distante do refinamento espiritual da tropologia? Nossa hipótese é que na imbricação entre 0 modelo tradicional da narrativa historiográfica e as inquietações exegéticas de Guibert, entre a literalidade e a tropologia, estabelece-se uma sutil relação que se exprime através (a) da razão pela qual Guibert decidiu se lançar em um tal projeto, (b) de sua avaliação da legitimidade dos testemunhos e (c) da noção abrangente e universal de uma história que se põe em movimento por e pela gloria de Deus. Não podemos nos esquecer também que a Dei gesta per Francos não é a sua única experiência narrativa e que a Autobiografia desempenha neste sentido um papel fundamental.

\section{A Historia e o homem interior}

0 primeiro historiador, e até onde sabemos provavelmente o único, a acentuar a relação entre a concepção de historia de Guibert de Nogent e o nível tropológico de interpretação bíblica foi J acques Chaurand em um artigo de 196533, cito: "A tropologia tende a se tornar o fim supremo da história como ela é habitualmente 0 da exegese: assim que ele se consagra a história, a leitura feita por Guibert do texto que constitui o conjunto dos fatos retidos é sob vários aspectos a mesma que em se tratando de uma passagem das Escrituras" ' (...) "A tendência a fazer predominar a tropologia opera na escolha dos elementos retidos. Guibert renuncia a designar pelo nome os cavaleiros

De statu interioris hominis (Richard de Saint-Victor. De statu interioris hominis), éd. J. Ribaillier. Archives d'Histoire et Doctrinale et Littéraire du Moyen Âge, 42 (1967), p.7-128 (p.61-128).

31 Para uma visão um pouco mais precisa sobre a especificidade da exegese de Guibert me permito citar GOMES, J ., Le cas singulier de l'exégèse de Guibert de Nogent, In: DAHAN, G. et NOBLESSE, A. (dir.), L'Exégèse Monastique de la Bible en Occident XII-XIV siècles. Colloque International de Strasbourg 10-12 sept. 2007, Paris: Institut d'Études Augustiniens [no prelo].

32 Ver toda a exegese de Zacarias 12, 1-2 no final do relato sobre a Primeira Cruzada: "Mas depois da tomada de J erusalém, 'todos os reinos da terra se reuniram contra ela': o que não se deve entender como uma alegoria, mas como a visão profética da nossa recente Historia" [Dei Gesta perFrancos, trad. Garand (nota 15), VII, p.261]; "Mas porque a liberdade da alegoria se daria ela seguimento através do emaranhado de palavras, quando a verdade da Historia nos impede de nos instalarmos entre conjecturas diversas?" [lbid., VII, p.262].

33 CHAURAND, J. La conception de l'histoire de Guibert de Nogent (1055-1124). Cahiers de Civilisation Médiévale, 3-4 (1965), p.381-395 e reeditado em CHAURAND, J. Les Paroles et les Hommes. Recueil de travaux inédits ou publiés revus et augmentés, Paris: SPM, 1992, p.27-53. Citaremos o texto a partir desta última edição. 
que fizeram em primeiro a sua entrada em J erusalém por causa do pecados dos quais muitos foram culpados após seu retorno: uma cruzada que não foi para seus participantes uma expiação seguida de um 'firme propósito' não representa mais nada aos olhos do autor"; e ainda, continua Chaurand, "as concepções de Guibertsão dependentes ao mesmo tempo de sua inclinação pela tropologia, que se exprime em particular no estudo das causas..."e, finalmente, "se há aqui um progresso do conhecimento histórico é legitimo vê-lo muito mais no refinamento da consciência que na descoberta de métodos bem posteriores a esta época".

Concordamos efetivamente com as proposições avançadas por Chaurand e lamentamos que passados quarenta anos depois da publicação deste artigo nenhum outro estudo tenha se debruçado sobre a questão. É preciso dizer que apesar das idéias citadas acima a principal preocupação do autor não foi a de se aprofundar na dinâmica da relação entre tropologia e historia. Para sermos inteiramente precisos, são bem poucos os trabalhos que se propuseram a abordar a relação entre a exegese e a narrativa historiográfica medieval, como os de G. A. Zinn J r. e de É. Mégier. ${ }^{34}$

Um primeiro ponto a serconsiderado é a forte reivindicação de Guibertem favor da autoria e do trabalho direto de escrita. Como é sabida, a composição de um texto medieval compreende, de maneira geral, diversas etapas que vão desde o "ditado" do mestre ao seu notário, que pode registrar o "texto" por uma primeira vez inscrevendo-o sobre o suporte dos tabletes de argila ou mesmo sobre um pergaminho de trabalho, este último certamente de qualidade inferior àquele reservado ao trabalho terminado; deste ponto o conteúdo enunciado passaria assim por múltiplas correções, desde um refinamento do pensamento à revisão gramatical e da própria transcrição, que durará mesmo até a transcrição final. Tal processo, assim bruscamente resumido, participa do problema delicado da nomeação de "autor" propriamente dito neste período, sem contarmos os remanejamentos posteriores do texto, sua transmissão e apropriação que pode fazer dele um objeto e um veiculo do exercício de uma autoridade que não será diretamente associada à pessoa do que atualmente poderíamos chamar "o autor". Neste último caso, se os textos de Guibert ganhassem o estatuto de obras autorizadas e autoritativas seria mais apropriado falar, como o faz Alain Boureau por Tomas de Aquino, de uma "mens Guibertus". Assim, nosso "autor" opta por um método de trabalho tão raro quanto a maneira pela qual ele o reivindica, ou seja, de se servir muito pouco ou nunca dos tabletes de argila e de pousar suas idéias diretamente sobre os fólios de pergaminho [figura 1].

34 ZINN J r., G. A., Historia fundamentum est.The role of history in the contemplative life according to Hugh of St. Victor, In: SHRIVER, G. H. (dir.), Contemporary Reflexions on the Medieval Christian Tradition. Essays in honor of Ray C. Petry, Durhan: 1974, p.135-158; MÉGIER, É., Il tempo dei monaci nella Historia duabus civitatibus di Ottone di Frisinga. Antecipazione dell'età dello Spirito di Gioacchino da Fiore?. Florensia. Bollettino del Centro Intemazionale di Studi Gioachimiti, anno 13/14 (1999/2000), p.281-296. Agradeço a autora por me ter dado a oportunidade de ler seu artigo. 
Sobre a composição do Moralia Geneseos que ele havia iniciado quando ainda era um simples monge no monastério de Saint-Germer-de-Fly e submetido à autoridade de um abade que o proibira uma tal atividade ele nos diz: Eu não sei se neste tratado eu me rendi útil a quem quer que seja, mas eu estou seguro que eu tenha agradado um grande número de homens letrados, e de toda maneira foi certamente para mim mesmo de uma grande utilidade: redigir me libera da ociosidade, que é o escravo dos vícios ${ }^{35}$. Sua grande necessidade de escrever o impulsionou, pois, em seus primeiros textos, a um exercício solitário e secreto, mas em seus últimos trabalhos já como abade do monastério de Nogent a atração e a importância do contato direto entre si-mesmo e seu pensamento não apenas permanece como parece ter se aprofundado. Na dedicatória a Norberto de Xanten, fundador de Prémontré, que abre o comentário da primeira série das Tropologiae in prophetis é assim que Guibert comenta as conseqüências de sua perda da visão: Eu estava habituado, quando podia escrever, a utilizar constantemente minha mão no lugar de uma mão estrangeira. Com efeito, no momento em que escrevia com minha própria mão, revisando freqüentemente minhas expressões com o olhar ao mesmo tempo em que escrevendo, nada me era mais fácil que de retomar o que eu poderia ter omitido; eu não tinha que me preocupar pois em contrariar meu secretário quando eu me atrasava, e eu podia velar escrupulosamente sobre a elegância do vocabulário, não me ocupando que de mim mesmo. Pois eu reúno mais à vontade em minha mente o que eu tenho a dizer que tenho menos razões de me enrubescer, sozinho comigo mesmo e livre de preocupações, da minha lentidão em formular meu pensamento ${ }^{36}$. $E$, no Prefacio da Dei gesta per Francos esta prática da escritura revela todo seu esforço: ... dado que eu faça nascer, ao grande esforço de gemidos, a obra que eu havia longamente elaborado em $\mathrm{mim}^{37}$, ou ainda, eu escrevi este relato compondo-o ao mesmo tempo, sem perder o tempo de retocá-lo com cuidado sobre os tabletes; a pena ele se arrancou dolorosamente de mim que eu o confiei, sem esperar, às folhas de pergaminho ${ }^{38}$.

35 Autobiographie, éd. Labande (nota 14), L. I, XVII, p.144.

36 HUYGENS, M. B. C. La Tradition Manuscrite de Guibert de Nogent, Steenbrugis, in Abbatia S. Petri et The Hague: M. Nijhoff, 1991, Appendice 20, p.112-113. Ver também GARAND, M.-C. Guibert de Nogent et ses Secrétaires, Turnhoult: Brepols (Corpus Christianorum Autographa Medii Aevi, II), 1995.

37 Dei gesta per Francos, trad. Garand (nota 16), Préface, p.47.

38 Idem, p.49. A dimensão dolorosa e física do processo de escrita reforçada por Guibert deve ser colocada em perspectiva, creio eu, com o relato em sua autobiografia de seu próprio nascimento : Minha mãe, próxima de seu termo, se encontrava presa durante quase toda a Quaresma a dores intensas e impróprias. Que por vezes ela me culpava desses sofrimentos assim que ela me via me distanciar, me precipitar em direção dos fatais precipícios ! Enfim brilhou o solene sábado, aquele da vigília pascal. Entretanto, as intermináveis torturas a transtornavam e, à aproximação se sua hora, esses tormentos não faziam que aumentar. Pensava-se que esse trabalho terminaria normalmente no nascimento ; pois eu me retornava, remontando profundamente em seu seio [Autobiographie, éd. Labande (nota 15), L. I, III, p.16-18]. O que nos parece importante ressaltar neste momento é a dimensão física que ganha a elaboração do texto sob a imagem de um parto doloroso; 0 «texto » como um verdadeiro corpo. A obra de Guibert é seu prolongamento e o testemunho de uma vida de retidão, re-significação por inversão da natureza pecaminosa que ele atribui a si mesmo desde de seu nascimento. Poderíamos pensar aqui em uma relativa feminização? Enfim, importa para o que diremos mais adiante a respeito da recusa da mediação entre pensamento e ato de escrita justamente esta idéia de extensão direta do autor sobre sua obra. Em u m outro 
Pode-se dizer, como o faz Monique-Cécile Garand, que se trata de uma verdadeira posição de escritor ${ }^{39}$. Mas o que significa queimar as etapas tradicionais de composição? Podemos ver imediatamente que o problema coloca-se além da simples escolha dos recursos técnicos de escrita, como ele se encontra também fora do campo restrito da mera liberdade de ação e pensamento. Guibert já é neste momento abade e as circunstâncias que poderiam influenciar negativamente sua disposição à escrever ou lhe privar do tempo necessário a esta atividade são as responsabilidades cotidianas de sua posição. Abolir as etapas tradicionais da composição significa de fato reuni-las, concentrá-las, em um único ponto, em uma única tutela subjetiva. 0 trabalho de composição é dessa forma muito mais intimamente ligado ao da meditação, ao da ruminação das idéias e de cada palavra que se inscreve antes no interior do autor mesmo antes de ser exteriorizada. Concomitantemente, se antes o processo de composição fraccionado se estendia no tempo, passando de mão em mão, de suporte em suporte, a maneira como Guibert imagina a escritura ideal presentificará o texto de uma só vez após todo um outro processo de reflexão espiritual; este último, por sua vez, não é linear, mas fruto de um movimento circular de introspecção que produz a tensão que forçará a mão à se render à pressão do espírito e ao desejo - que é também uma necessidade - de comunicação. Este movimento circular, incessante, de meditação e de reflexão, é ele também estrangeiro ao passado e incapaz de futuro, fora daquele, escatológico, ao qual ele está submetido. Pela natureza desse duplo balizamento temporal e concentração do processo de composição do texto e da escritura resume-se também ao presente contínuo - imagem, mas apenas imagem, do movimento celestial pseudo-dionisíaco de uma mente inquieta antes do repouso do Sabath..$^{40} \mathrm{Uma}$ das características particulares da interpretação tropológica de Guibert de Nogent é justamente aquela de indicar, descrever e explicar os mais variados "movimentos da alma" (motus animi) com a intenção de apaziguar os que são indesejáveis, os "movimentos animais", ou aqueles da vontade desregrada por exemplo, em função da liberação excelente daqueles considerados como os mais elevados, como os "movimentos racionais" ou "intelectuais". Vemos então qual é o trabalho sobre si, me servindo aqui de uma expressão de Michel Foucault, que precede e que deve preceder a exteriorização textual. Na verdade, esta textualização da interioridade é fundamental para a compreensão do papel da Idade Média na constituição da "pessoa" ou, dito de uma maneira mais polêmica, do indivíduo. 0 texto, por fim, não é algo deixado como trabalho

sentido, GUERET-LAFERTE, M. La conception du devenir dans le De Vita Sua de Guibert de Nogent, In: BAUMGARTNER, E. et HARF-LANCNER, L. (dir.), Progrès, Réaction, Décadence dans l'Occident Médiéval, Genève: Droz, 2003, p.49-63 (p.58-59) associa a imagem do nascimento doloroso de Guibert à fundação do monastério de Nogent tal como ele o transmite.

39 GARAND, M.- C. (nota 38), p.24.

40 Ver: MÉGIER, É. (nota 34), p.293. 
final, mas torna-se um lugar ao qual se deverá retornar. Trabalho de meditação, trabalho de escritura, trabalho de memória.

Outro ponto que se coloca em jogo é a intenção e a dignidade singular de cada pessoa sobre as quais é preciso ter-se a maior clareza possível. Para Guibert, para além da salvação da alma individual existe ao mesmo tempo uma responsabilidade coletiva implicada diretamente na conduta daqueles homens pressupostos a serem os guias de uma certa comunidade. Do infeliz destino da cidade de Laon, por exemplo, Guibert extrai a razão com base na falta de retidão moral de seus bispos. Mas a exegese de nosso autor nos ajuda a compreender mais intimamente seu modo de trabalho, que coloca em cena um jogo de desdobramentos e prolongações de um único e mesmo movimento que possui como referência maior à efetivação do que poderíamos chamar de uma "voz profética"; este movimento é a imagem do fluxo continuo da mensagem divina que é transmitida pela inspiração do Espírito Santo aos eleitos e que ganha materialidade através destes últimos. A realização terrena da mensagem divina pode se manifestar, por fim, tanto em uma obra de predicação e doutrinamento, como é o caso do comentário sobre os profetas realizado por Guibert, ou em um texto, como a Bíblia, que é o registro supremo de todos esses fenômenos. No entanto a "voz profética" à qual aspira Guibert não se apresenta e não poderia se apresentar a ele da mesma maneira pois isso equivaleria a afirmar que entre ele e os eleitos de Deus não existiria nenhuma diferença. 0 programa iconográfico elaborado por Guibert em pessoa para acompanhar o texto das Tropologias nos servirá como exemplo. Ele estabelece a devida hierarquia que convém na inicial ornamentada que abre o comentário sobre $\mathrm{Amos}^{41}$, na qual a pomba que representa o Espírito Santo pousa sobre a mão direita de Amos que ao mesmo tempo sopra a palavra através de um curto trompete diretamente no ouvido direito da cabeça de Guibert [figura 2]. Esta cena se desenrola inteiramente no interior e compõe ao mesmo tempo a maiúscula "V" de Verba Amos... ("Palavras de Amos...", Amos 1,1). Este é o caso também da inicial ornamentada "A" do nome de Amos que abre o prólogo deste mesmo comentário [figura 3]. ${ }^{42}$ Desta maneira não é o Espírito Santo que entra em contato direto com 0

41 BnF lat. 2502, f. 101r. Ver também a explicação geral de SMALLEY, B. The Study of the Bible in the Middle Ages, Notre Dame (Indiana): University of Notre Dame Press, 1978, p.12: "A necessary part of his [Origen] whole system, and also part of his inheritance from Christian tradition, was the view that the interpretation of Scripture was a grace or 'charisma'. Origen's pupil, St. Gregory Thaumaturgus, believed that his master shared the inspiration of the sacred writers themselves: the same Spirit which inspired the prophets inspired Origen to interpret their prophecies. The claim will be made subsequently for other great maters of the mystical interpretation. The Holy Spirit speaks through the mouths of St. Gregory the Great and of St. Bernard of Clainaux when they expound Scripture. $J$ ust as the evangelists are represented in medieval iconography as writing at the dictation of angels, St. Gregory, composing his commentaries, listens to a dove which perches on his shoulder with its bill to his ear. All this goes back to Origen's teaching."

42 Esta primeira inicial é sensivelmente mais complexa que a segunda. Aqui, o profeta se encontra sentado e a pomba do Espírito Santo está pousada sobre seu ombro direito com seu bico tocando intimamente o seu ouvido, sem distância, sem mediação sugerida. Como resultado desta ação o profeta é mostrado escrevendo sobre um longo filactério que liga a figura de Guibert, mais abaixo e à esquerda da imagem, como que inserido no interior da letra, àquela do Cristo, mais elevada e no extremo oposto, à direita da imagem. Sem que possamos ir muito mais além, 
abade de Nogent, mas é a palavra profética que se erige como meio através do qual ela se torna inteligível e acessível aos homens capazes, é bem verdade, de interpretá-la corretamente. A série transmissiva deste fluxo continuo que é a graça divina é uno, como o compreende Guibert, e o texto que se segue após a imagem de introdução deve ser ele também considerado como parte integrante desta grande imagem que no limite é o manuscrito como um todo, representação iconográfica em seu sentido mais amplo possível da unidade e da hierarquia entre os diversos veículos pelos quais a palavra ganha toda a sua visibilidade, mas também a representação corpórea - um corpus - em nível análogo, reforçando ainda mais a idéia de que o trabalho de escrita para Guibert se liga invariavelmente a um desdobramento físico como metáfora de um movimento interior. Desta maneira o manuscrito - os manuscritos assim orientados por Guibert - são de fato o que se vê neles e tudo o que significam enquanto procedimento hermenêutico intrinsecamente associado à subjetividade e à interioridade monástica ${ }^{43}$. A interposição de um notário no interior de uma tal lógica só viria a macular o que deve ser, no final, absolutamente "digno de fé", como veremos adiante. A meditação e a análise quase psicológica da tropologia é fundamental neste sentido, e assim a voz profética e o curso da história podem entrar em plena harmonia: Não é uma confiança qualquer em meu saber literário, para dizer a verdade bastante fraco, que me deu a audácia extrema de realizar essa modesta obra, mas a autoridade de uma historia espiritual (historiae spiritualis auctoritas): pois eu sempre tive por certa que a potencia divina somente havia ordenado o cumprimento e escolhido os atores; eu não duvidei tão pouco que Deus

cabe fazermos duas observações: a primeira, refere-se à posição ocupada pelo Cristo nesta primeira imagem e a posição de Guibert na segunda. Elas são completamente análogas e praticamente idênticas; a mesma frontalidade extática, a mesma cabeça isolada da qual partirá por fim o restante do texto e aue é assim o final imagético do movimento expresso e intrínseco às duas imagens. Em segundo lugar, é a função auditiva, metáfora comum na Idade Média da transmissão de uma palavra imaterial e transcendente, que é colocada em relação com o ato de escrever. Por um lado temos o profeta tocado intimamente no ouvido pela pomba e que escreve, e por outro lado Guibert tocado pelo trompete e que é, evidentemente, o « escritor »do comentário lançado em seguida, pela próxima letra. De uma maneira que não pode deixar de nos surpreender, Guibert faz corpo com seu texto como o Cristo faz corpo com a palavra do Antigo Testamento, como ele faz corpo como inciador geral de toda a obra; por fim, como o Cristo faz corpo com Guibert da maneira como este últmo se performatiza em elemento textual imbricado na composiçãp de sua própria obra. No sentido da análise que nos interessaria para estas duas imagens - três, na realidade pois devemos incluir a primeira de todas que abre toda a série de Tropologias - ver o estudo inspiradorde BONNE, J.-C., L'image de soi au Moyen Âge (IXe-Xlle siècles). Raban Maur et Godefroy de Saint-Victor, In: GENTILI, A., MOREL, Ph. e VIA, C. C. (dir.), II Ritratto e la Memoria [materiali 2], Roma: Bulzoni editore, s/d, p.37-60.

43 À orientação iconográfica corresponde também uma nova orientação na apresentação do texto em si; Guibert está entre os melhores exemplos da nova tendência de separação canônica das letras e das palavras do manuscrito, como nos mostra o já clássico trabalho de SEANGER, P. Space Between Words. The Origins of Silent Reading, Stanford: Stanford University Press, 1997, p.244 e 249, e sua apreciação dos mss. Paris, BN lat. 2500, 2502 e 2900: «The adoption of separeted writing sparked an interest in autograph composition, creating the possibility of more intimate expression on the part of the author. With the renewed desire of authors to write their own works, certain of them, such Othlon of Saint-Emmeran in the eleventh century and Guibert of Nogent inte twelfth century, expressed sentiments hitertho not set down on parchement because of the lack of privacy when composition depended upon dictation to a secretary. Eschewing secretaries, Guibert wrote in private, and his mastery of the medium of separated script penetrated into his own consciousness as an author » (p.249). 
houvesse designado aqueles, tão incultos fossem eles, pelos quais Ele teria desejado que esta História fosse escrita ${ }^{44}$.

Uma segunda característica da obra historiográfica de Guibert aparece na razão pela qual ele se decidiu a escrever uma historia da Primeira Cruzada. Após o termino e o retorno da expedição dez narrativas foram realizadas em um período extremamente curto de tempo, e Guibert esta longe de ter sido o primeiro a narrá-la, sendo aproximativamente 0 oitavo ou o nono a fazê-lo ${ }^{45}$. Um desses textos que chegou às mãos de Guibert foi o relato anônimo de um participante da aventura, a bem conhecida Gesta francorum ${ }^{46}$. Após a leitura do texto a reação de Guibert é taxativa e explicitamente monástica: Eu me exponho assim, com tanta temeridade quanto descaramento - mas impelido pelo meu amor pela fé -, a sofrer as críticas de outrem; quando se descobrirá que eu empreendi este trabalho para comigir uma outra obra, talvez julgar-se-á a segunda versão pior que a primeira. Entretanto, pois que eu via o ardor com o qual se estuda por toda parte a gramática; pois eu soube como os homens mais vulgares tinham acesso a ela, graça à multiplicação das escolas - me foi insuportável renunciar à descrever esta gloria de nosso tempo (senão como eu devia, ao menos como eu podia), ou mesmo de abandonar a história ao desgaste de um discurso sem arte ${ }^{47}$. A posição explicitada por esta passagem põe em jogo a noção de autoridade tal como dissemos acima, pelo fato de não apenas executar uma outra obra em contraponto a anterior, mas sobretudo por se servir diretamente desta, por muitas vezes mesmo textualmente, para re-significar toda a narrativa e com isso re-significar a história, visto que ela se apresenta em sua evidência enganadora como objeto, ela também, de uma leitura exegética. E Guibert se serve também do conteúdo da Gesta francorum para verificá-lo com base nos testemunhos que ele pôde recolher daqueles que participaram diretamente da expedição, não poucos e não todos desconhecidos de um homem tão próximo da aristocracia senhorial da região de Laon, Soissons e Beauvais. 0 que se subentende sob uma crítica antes

44 Dei Gesta per Francos, trad. Garand (nota 16), Preface, p.45; Ver também: ARDUINI, M. L. 'Historiae spiritualis auctotitas' (Dei Gesta per Francos, Praefatio) e 'Retrovaga vestigia' (De Vita Sua, II, 4) : storia e memoria autobiografica in Guiberto di Nogent. AEVUM, 76: 2 (2002), p.271-307.

45 Cito aqui a ordem cronológica oferecida por BRESC, H. Les Historiens de la Croisade. Guerre Sainte, J ustice et Paix. Mélanges de l'Ecole Française de Rome, t. 115 (2003), 2, p.727-753 (p.727 note 2): GEOFFROI MALATERRA, De rebus gestis Rogerii, éd. E. Pontieri, Bologne, 1928 (RIS, V-1) ; as cartas publicadas por H. Hagenmeyer, Epistulae et chartae ad historiam primi belli sacri spectantes. Die Kreuzzugsbriefe aus den J ahren 1098-1100, Innsbruck, 1901; Gesta Francorum expurgantium Iherusalem, éd. et trad. L. Bréhier, Paris, 1924 (Histoire Anonyme de la Première Croisade); RAYMOND D'AGUILERS, Historia Francorum qui ceperunt J erusalem, éd. J. Hugh et L. L. Hill (Le « Liber » de Raymond d'Aguilers), Paris, 1969 (Documents relatifs à l'histoire des croisades, 9); PIERRE TUBEDOBE, Historia de hierosolymitano itinere, ed. J. H. Hill e L. L. Hill, Paris (Documents relatifs à l'histoire des croisades, 12), 1977; FULCHER DE CHARTRES, Gesta Francorum Iherusalem peregrinantium, dans Receuil des historiens des croisades. Historiens occidentaux, III, Paris, 1856, p.717-822 ; ROBERT LE MOINE, Historia iherosolimitana, Ibid., III, p.717-822; BAUDRI DE BOURGUEIL, Historia J erosolimitana, Ibid., IV, Paris, 1879, p.01-111 ; GUIBERT DE NOGENT (nota 14); RAUL DE CAEN, Gesta Tancredi, dans Receuil des historiens des croisades. Historiens occidentaux, IV, Paris, 1856, p.603-716. Acrescente-se à essa lista, mas não entre os "cronistas" ou "historiógrafos" medievais da Primeira Cruzada, WILLIAM DE MALMESBURY, Gesta regum anglorum, ed. e trad. R. A. B. Manors, Oxford, 1998 e GUILLAUME LE CHANCELIER, Bella Antiochena, ed. H. Hagenmeyer, Hiedelberg, 1896.

46 éd. L. Bréhier (nota 45).

47 Dei gesta per Francos, trad. Garand (nota 16), Prefacio, p.46. 
de tudo de estilo, de excelência literária é que, para Guibert, esta dimensão discursiva é parte essencial de um certo critério de verdade. De uma verdade que não se contenta em permanecer enclausurada nos fatos, mas que se deve tornar manifesta através da narrativa e da compreensão das causas, como já assinalara Chaurand. É todo um procedimento hermenêutico que se estabelece para que este sentido e esta verdade possam ser ditas; uma relação entre a capacidade interpretativa do autor e seu cuidado na coleta dos fatos. 0 meio no qual se dá a elaboração destes dois elementos é justamente o espaço subjetivo da pessoa que deve compreender tão bem as vicissitudes e a dinâmica dos movimentos da alma quanto os eventos exteriores. Guibert, em mais de uma ocasião lançou mão da analogia, pautada em sua reflexão tropologica, entre mundo interior e mundo exterior de modo a deixar claro de que maneira a ordem social tão bem quanto a da comunidade regular, é o espelho e o resultado de uma boa ou de uma má disciplinarização das vontades e dos afetos ${ }^{48}$.

Antes de concluirmos nossa apresentação é necessário que nos atardemos sobre a noção de testemunho. Como foi exemplarmente demonstrado por Bernard Guenée ${ }^{49}$, e mais recentemente por Elizabeth Lapina ${ }^{50}$, a validade e toda a credibilidade aportadas por uma narrativa repousa geralmente sobre a visão direta, ou seja, sobre a experiência imediata daquele que se presta a torná-la conhecida. A visão, pois, como representação sensível da apreensão mais intima de um acontecimento. Ora, é exatamente este o estatuto do autor anônimo da Gesta francorum e que é colocado em segundo plano por Guibert face ao critério de verdade pautado na excelência textual, indício de excelência interior. Eis uma das passagens mais interessantes da Dei gesta de Guibert: Ninguém, de acordo com meu julgamento, esta no direito de criticar minha empresa presente. Sem dúvida não fui à J erusalém; sem dúvida não conheci a maior parte dos personagens e dos lugares dos quais eu falo; mas eu não creio que isto prejudique em nada a utilidade geral de minha obra, pois que eu estou certo de ter contado, ou de me preparar a contar, fatos que eu apreendi através de testemunhos verídicos. Se me acusam de não ter visto, não podem me acusar de não ter ouvido $0^{51}$; e eu acreditaria completamente que vale tanto ouvir que ver. É verdade que 'o espírito é menos vivamente tocado disso que lhe é transmitido pelo ouvido que pelos quadros oferecidos ao contato fiel dos olhos [Horacio, Arte poética, 120-21]'. Quem duvidaria

48 Assim, o sermão para a reconciliação da catedral de Laon após o assassinato de Gérard de Quierzy cometido em seu interior é exemplar: Autobiographie, éd. Labande (nota 15), L. III, VI, p.306-310. O comentário dos Salmos 67, 2-3 e 77, 49 como de Jer. 4, 10 e de Luc. 2, 35 até onde pudemos verificar nos parecem completamente originais.

49 GUENEE, B. (nota 3). Com uma abordagem que não privilegia, no entanto, os textos historiográficos : NEWMAN, B. What did mean to say «I saw »? The clash between theory and practice in Medieval visionary culture. Speculum, 80 (jan 2005), 1, p.1-43.

50 LAPINA, E. 'Nec signis nec testis credibus...': the problem of eyewithnesses in the chronicles of the first crusade. Viator, 38/1 (2007), p.117-139.

51 Vemos mais uma vez a importância da metáfora auditiva. 
portanto que os historiadores, ou que aqueles que publicaram as Vidas de santos, não tenham escrito não somente o que eles viram com seus olhos, mas o que eles souberam pelas relações de um outro? Se, como podemos ler nas Escrituras, o homem sincero 'testemunha do que ele viu e ouviu [J oão $3,32]$ ', então, o relato autêntico daqueles que dizem certamente a verdade merece ser crido, já que não podemos ver por nos mesmos. Se então alguém me culpa ou despreza minhas tentativas, ele é sempre livre de corrigi-las; se ele o desejar, se meus escritos o desagradam, que ele redija os seus ${ }^{52}$.

Uma defesa tal dos direitos da intermediação não deve nos espantar. Vemos aqui em que grau, em negativo, o testemunho direto se apresentava no início do século XII como largamente mais fiável que a coleta de informações de segunda mão, viessem elas dos textos ou de pessoas interrogadas diretamente. Os problemas relativos à credibilidade e à veracidade da evidência não são simplesmente historiográficos e no que toca a reflexão exegética e litúrgica de Guibert ela se mostra essencial. Quando a oportunidade de falar e de se posicionar a respeito da grave polêmica eucarística do período se apresentou a ele através da demanda de Siegfried, prior de Saint-Nicholasaux-Bois - eà partir de 1120 abade de Saint-Vincent de Laon - , em meio a toda a controvérsia sobre a participação ou não de J udas no mistério da eucaristia e o estatuto do pão e do vinho, a questão de se crer ou não naquilo que não vemos ressurge, como por exemplo na remissão dos pecados depois do batismo, nos suplícios do inferno, nas recompensas do reino de Deus etc ${ }^{53}$. $\mathrm{E}, \mathrm{o}$ que é ainda mais interessante, Guibert afirma que tal como as imagens representadas nas igrejas os sacramentos são como monumentos para os olhos dos simples e que para os sábios eles não tem nada a oferecer ${ }^{54}$. A problemática sobre a definição do signum e da figura neste período abre largas margens a especulações radicais que se congregam no campo da estrita exemplaridade dos gestos e dos fatos, dissociando assim o efeito de sua origem visível. 0 que se preserva aqui, no interior do pensamento de Guibert como exegeta, é a capacidade de interpretação que se eleva, alimentada e alimentadora do controle e do conhecimento da interioridade humana em direção à sabedoria, o Intellectus segundo Guibert: o mais próximo de Deus e o mais imóvel entre todos os movimentos da alma.

Uma passagem do Liber quo ordine semo fieri debeat, escrito por volta de 1113, entre sete e dois anos depois do Dei gesta per Francos, torna mais

52 Dei gesta per Francos, trad. Garand (nota 16), IV, p.133-134. Será útil de compararmos a maneira pela qual Guibert se serve aqui da passagem dos Evangelhos de J oão com uma outra, que expressa a mesma idéia também em J oão mas 19, 35 («é aquele que viu que rende testemunho ») utilizada pelo papa Pascal II, segundo Guibert, para refutar sua argumentação hesitante com relação à eleição de Gaudry como bispo de Laon. Autobiographie, éd. Labande (nota 15), L. III , IV, p.288.

53 GUIBERT DE NOGENT, Epistola de buccella J udae data et de veritate Dominici corporis, PL 156, col. 532C. Ver também Dei gesta per Francos, trad. Garand (nota16), L. I, p.58.

54 Idem, col. 531A. Ver: RUBENSTEIN, J. Guibert of Nogent. Portrait of a medieval mind, New York/London: Routledge, 2002, p.134-138. 
clara a posição de Guibert quanto à experiência, direta e indireta. Ele se serve da situação particular da testemunha ocular que antes havia sido convocada como justificativa e explicação da redação de sua obra "historiográfica" fazendo-a deslizar aqui em direção ao campo da instrução predicativa e exegética, onde ela se transforma em metáfora bélica sobre o valor da experiência espiritual: Qualquer homem, mesmo um sem experiência, um que nunca tomou parte em uma batalha, pode muito bem falar da guerra, simplesmente porque ele viu guerreiros ou ouviu histórias sobre a guerra; mas que diferença existe entre este homem e o outro que pode rememorar a guerra, que nela lutou ou foi atacado, que fez a guerra et a sofreu! A situação é a mesma quanto às questões espirituais quando nós escutamos o discurso eloquente sobre o que eles leram nos livros ou escutado de outros; quão grandemente eles diferem do homem que fala com uma real autoridade sobre suas próprias lutas espirituais, do qual a experiência é como uma marca a fim de sublinhar o que ele diz, do qual a consciência é a testemunha do que sua boca diz ${ }^{55}$. A problemática do testemunho possui portanto uma dupla valência, quando ela se refere aos olhos carnais ou aos olhos da mente, quando se trata da experiência mundana ou da experiência interior. Sem levar em consideração esta diferença a passagem acima parece quase contradizer a defesa que Guibert havia avançado em favor do Dei gesta. Na verdade, a hierarquia entre a participação direta do guerreiro e a introspecção clerical (de fundo evidentemente monástico em Guibert) nunca é colocada em dúvida e está também implicitamente presente na exigência da fiabilidade dos testemunhos colhidos para a composição da narrativa. Em resumo: há antes a experiência mundana, superada pela experiência humana geral que se apóia na fé, sendo esta última superada em seguida pela experiência espiritual do exegeta e do predicador. É a diferença feita, pois, entre o acontecimento sem interpretação, o acontecimento sob um primeiro nível de interpretação (historia), a metáfora bélica (allegoria) e 0 fato espiritual (tropologia) no Quo ordine semo fieri debeat.

Assim, como em linhas gerais o é também para Abelardo, será Deus a melhore a única testemunha das intenções subjetivas e narrativas de Guibert, contrabalançando o próprio julgamento do abade de Nogent sobre as suas fontes orais, dignas de fé devido ao seu comportamento, signo de uma alma pia ${ }^{56}$ : Eu aprendi de homens verídic os que participaram à divina expedição, eu tomo Deus em testemunha... ${ }^{57}$. E da mesma maneira pela qual Deus é o agente primeiro de toda a dinâmica espiritual humana ${ }^{58}$, ele é o principio significativo

55 GUIBERT DE NOGENT, Liber quo ordine sermo fieri debeat, éd: M. B. C. Huygens, Turhout: Brepols [CCCM 127], 1993, p.57-58.

560 relato autêntico daqueles que dizem certamente a verdade [Dei gesta per Francos, trad. Garand (nota 16) L. IV, p.134].

57 Ibidem, VII, p.240.

58 Me permito remeter à minha apresentação «Guibert de Nogent, commentateur de la Bible »(Penserl'Eglise, penser la société au Moyen Âge, J ournée de médievistes du CNRS-Université de Bourgogne, Dijon, 14 avril 2006): Dans le début du commentaire sur J onas (Tropologiae in prophetis, Paris BnF lat. 17282, f. 44v-45v), par exemple, les deux 
e transcendente da Historia: Ele que havia realizado, por seu intermédio [dos Francos], tão grandes coisas que nem eles mesmos que haviam sido os atores, nem nenhuma outra pessoa, podiam apreciar todo seu valor ${ }^{59}$.

Podemos concluir, portanto, tentando esboçar um principio de resposta à questão que nos havíamos colocado no inicio sobre a relação entre o nível literal ou histórico e o nível tropológico. Ao que nos parece a obra de Guibert apresenta uma coexistência hierarquizada entre os fatos (a literalidade), a interpretação destes mesmos fatos (neste caso a tropologia fortemente subjetivada) e o principio dinâmico geral (Deus), mas que esta hierarquia é menos de dignidade do que de sentido, posto que estes três elementos são a base e o núcleo da compreensão e da razão de existir dos acontecimentos. Este equilíbrio entre esferas de início distanciadas se mantém sobretudo devido à exigência hermenêutica em se preservar ao máximo possível, e o mais precisamente possível, a factualidade - justamente a característica da obra de Guibert que mais havia chamado a atenção dos historiadores do final do século XIX e inicio do XX - ao mesmo tempo em que se deve buscar a retidão interior necessária para tanto. Tendo garantido a fiabilidade dos relatos escritos e dos testemunhos recolhidos é possível passar a outros níveis de compreensão, como é de fato o procedimento geral dos comentários bíblicos. $O$ sentido da narrativa, ao final, é duplo: não apenas evidenciar e compreender a ação e a vontade divina na História, mas proceder a uma interiorização pessoal que possa tornar o narrador digno dos fatos que ele pretende relatar e vice-versa. 0 método de trabalho de Guibert e todo o seu rigor é o que na verdade libera das malhas da literalidade à qual elas se atêm todas as possibilidades introspectivas contidas na originalidade de sua exegese tropológica. A letra, que é evidentemente o texto e ao mesmo tempo um dos sentidos da leitura - primeira - da sacra pagina é, ela também, a realidade e uma primeira aproximação da res deste mundo e é por esta razão que a exegese medieval e sobretudo aquela que se realiza a partir do século XII pode ser dita "totalizante". Mas neste grande quadro conjuntural é possível observarmos suas matizes e descontinuidades, como o caso de Guibert nos ensina.

Portanto, sem abrir mão deste principio de unidade e de totalidade, o abade de Nogent parece estabelecer entre a letra e a interioridade uma distância, sem que esta se resolvesse em uma fronteira, de modo que possamos

convocations «Lève-toi! [Surge]» adressées au prophète sont interprétées de façon très similaire ; la première, venant de Dieu, initie le mouvement général en nous incitant à abandonner la lenteur et les anciennes torpeurs [a lentitudine veteris torporis tui excudere], et c'est encore Dieu qui met en mouvement tout l'espace intérieur quand il souffle le vent sur la mer. La seconde, venant du capitaine du vaisseau, qui représente à ce moment la raison qui avance à l'intérieur de l'âme et qui modère les intempéries de la conscience, réveille l'homme des torpeurs de l'esprit [torporis mentis]. Ainsi, le processus qui mène à la contemplation se fait sous l'impulsion des ces deux niveaux dynamiques et dans une certaine mesure complémentaires. Ver também : DAHAN, G. L'Exégèse médiévale du livre de J onas. Cahiers Evangile (supplement 110), s/d, p.91-104.

59 Dei gesta per Francos, trad. Garand (nota 16), VII, p.244. Esta entre muitas outras citações do mesmo gênero presentes por todo o relato. 
considerá-la como a conseqüência de seu método exegético, interpretativo, e de sua experiência narrativa. Esta distância, difícil de ser conceituada, foi tida até o momento como a marca da impenetrabilidade entre a exegese e a crônica, principalmente por cada um destes universos serem tão fortemente submetidos à rigorosos modelos, lançando mão de imagens e fórmulas discursivas largamente partilhadas. Ainda há muito a ser feito neste sentido e nossa propria exposição sobre esta parte da obra de Guibert de Nogent está longe de se pretender conclusiva. Seria ainda necessário incluir de maneira crítica à analise aqui iniciada a questão sobre o lugar ocupado pela "autobiografia", as Monodiae, procurando ver neste texto também de que maneira poderia esta organizada esta hierarquia dos sentidos interpretativos e em que nível ela define essencialmente uma narrativa de si por um exegeta tão ligado às virtudes da tropologia. A distância indicada acima não é nem simplesmente formal nem mesmo de gênero literário - se este último critério pode ter alguma relevância para o período ao qual nos interessamos. Ela é hermenêutica, se exprimindo na apreensão espiritual dos fatos e dos textos por parte do monge e na sua expressão textual, a qual o monasticismo do século XII, principalmente entre os cistercienses e premonstratenses, definiu como "experiência": Hoje - diz Bernard de Claivaux - nós lemos no livro da experiência. Retornem-se em direção à vocês mesmos [Convertimini ad vos ipsos], e que cada um interrogue sua consciência sobre o que deveria dizer, ou ainda, comentando o terceiro beijo do Cântico dos Cânticos: enfim, tendo já uma dupla experiência de complacência divina graças a esses dois beijos você pode talvez pretender à experiências mais santas sem temor de se confundir. Pois à medida em que você cresce na graça, você se sente também se dilatar na confiança ${ }^{60} \mathrm{~A}$ expressão "livro da experiência" me parece extremamente justa para o que tentamos evidenciar aqui, reunindo a questão do texto, da escrita e da inscrição em si, e o misticismo particular da época mediado pelo recurso à palavra, à predicação e à meditação.

Enfim, a plena reunião do "ator", "autor" e do "testemunho visual" se dará, justamente, na autobiografia, a de Guibert e certamente a de Abelardo, na qual a conjunção das temporalidades exteriores e interiores será o terreno de exercício de uma nova perspectiva sobre a memória e a história, sete séculos antes, portanto, da longa e definitiva dissociação entre o olho e a experiência, entre e evidência e os fatos, que são a memória sísmica da cisão epistemológica que se deu no seio das ciências sociais na segunda metade do século XIX. Atualmente, algumas tentativas isoladas, mas nem por isso menos interessantes, foram feitas no sentido de re-implicar a experiência e a historiografia - como dizia Guibert, experientia autem nichil humanae menti

60 BERNARD DE CLAIRVAUX, Sermons sur le Cantique, t. I, Paris: Cerf [Sources Chrétiennes, 414], 1996, p.101 e p.109. 
utilius est ${ }^{61}$ - , pensando em ir mesmo mais longe que a evidência da presença subjetiva do autor-historiador que nos é desde alguns anos já bastante familiar ${ }^{62}$, revelando assim um momento de vulnerabilidade - que do ponto de vista de um Guibert de Nogent seria uma das condições da narrativa fiável - em que o inconfessável para nós poderia ser dito assim: Eu não tenho necessidade de nada saber sobre mim. Aqui tudo é claro. Não, tudo não é claro. Mas é preciso que o discurso se faça. Então inventamos obscuridades. ${ }^{63}$

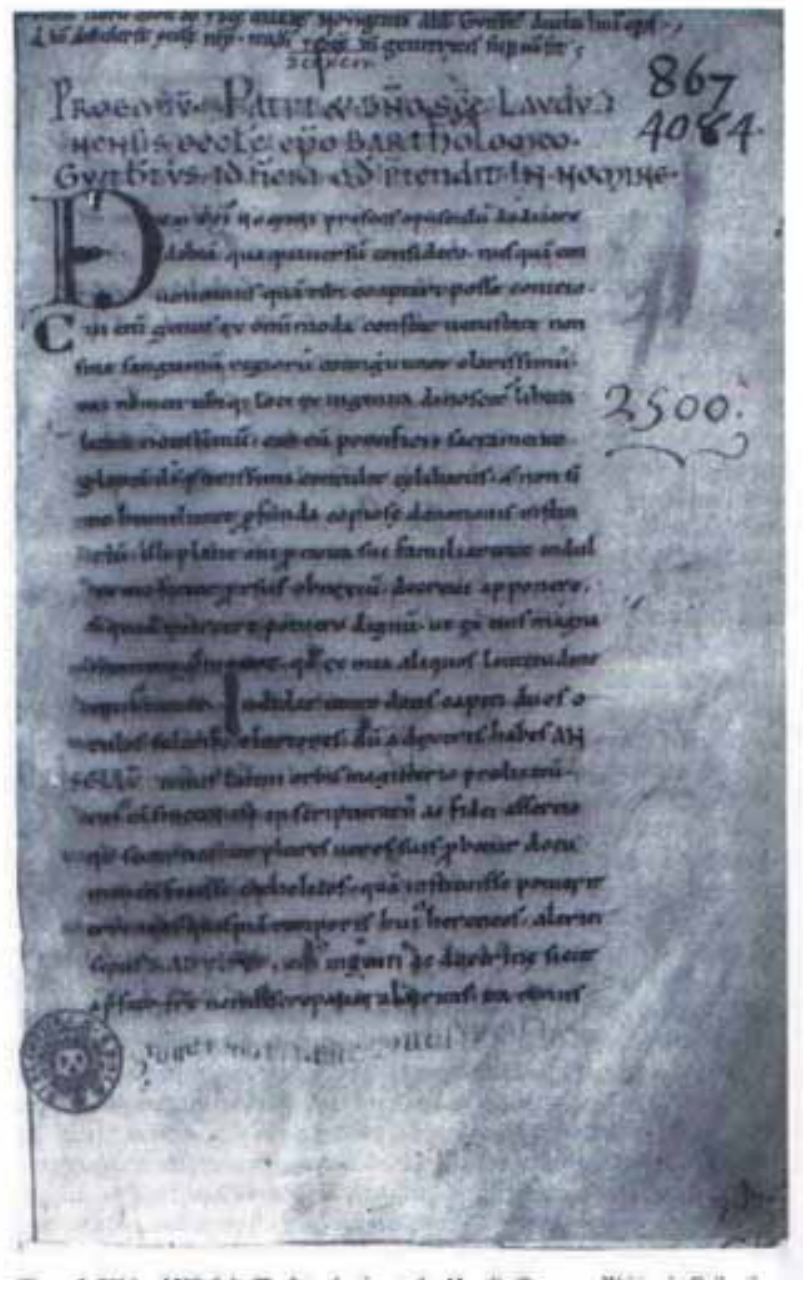

Figura 1: Paris BN lat. 2500, f. 1r. Introdução do Moralia Geneseos, escrito com a mão de Guibert.

61 GUIBERT DE NOGENT, Liber quo ordine sermo fieri debeat (nota 55), p.56.

62 Penso principalemente nos trabalhos de AGAMBEN, G. Enfance et Histoire, Paris: Petite Bibliothèque Payot, 2002; MILO, D. S. Trahir le Temps (Histoire), Paris: Les Belles Lettres, 1991; MILO D. S. et BOUREAU, A. (dir.), Alter Histoire. Essais d'Histoire Expérimentale, Paris: Les Belles Lettres, 1991. Ver também: CALAME, C., Pour une anthropologie des pratiques historiographiques. L'Homme, 173 (jan-mar 2005), p.11-45.

63 BECKETT, S. L'Innommable, Paris: Ed. de Minuit, 2004 (1953), p.12. 


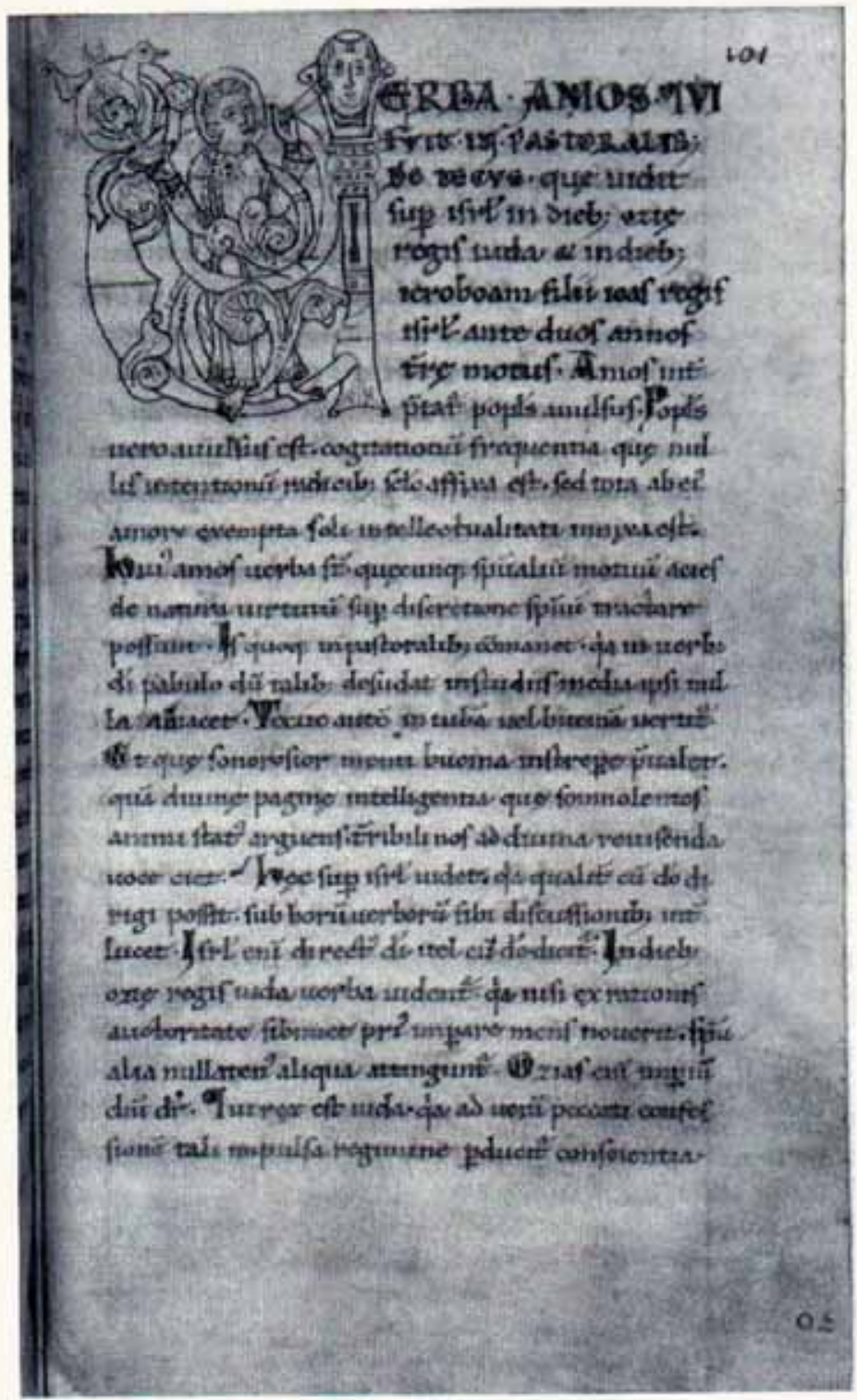

Figura 2: Paris BN lat. 2502, f. 101r. Início do comentário de Amos. 


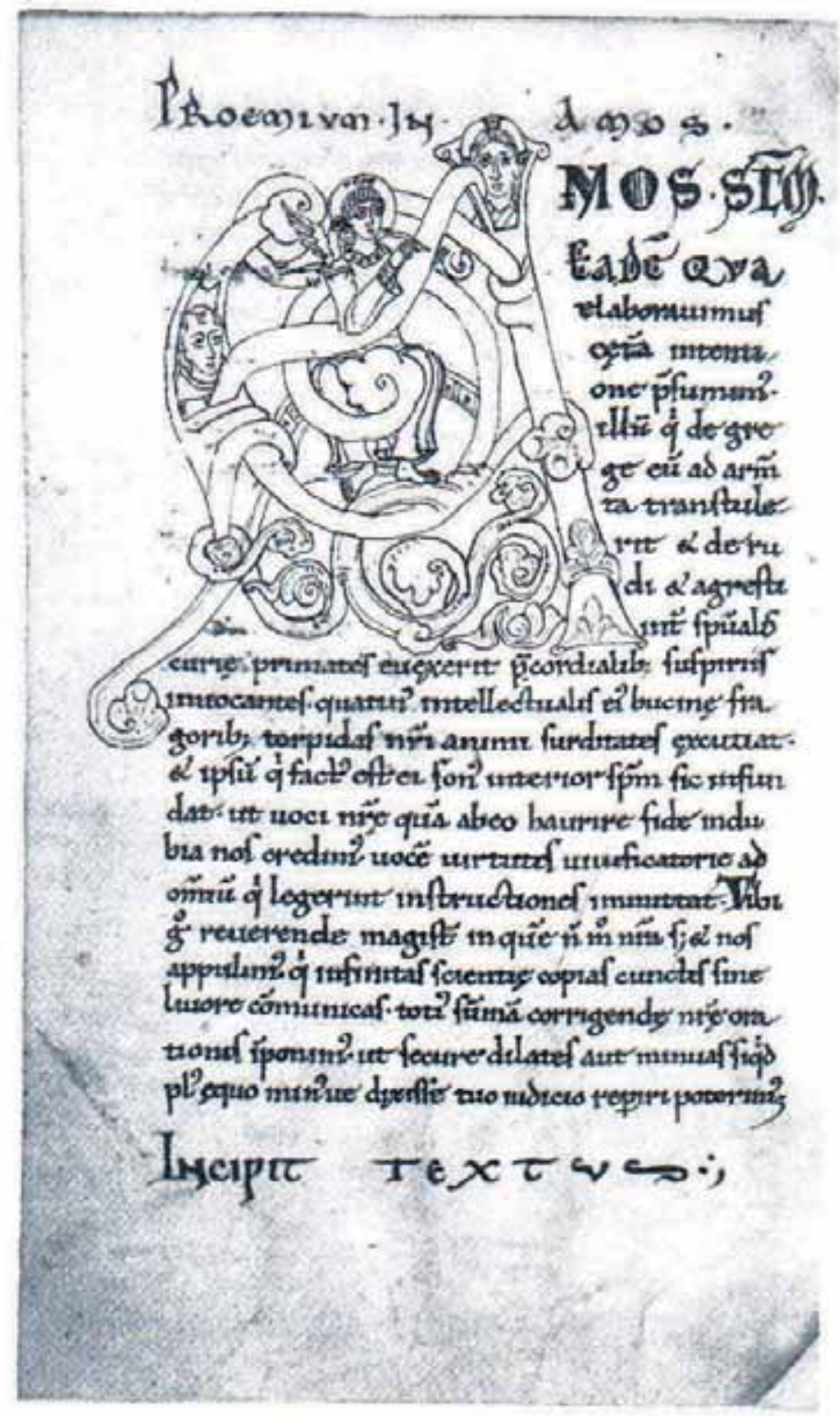

Figura 3: Paris BN lat. 2502, f. 100v. Prólogo do comentário sobre Amos. 